\title{
The effects of intervention on frequent attenders' adherence to health regimens, depression, somatization and hypochondriasis
}

\author{
Sari Hirsikangas ${ }^{* 1}$, Outi Kanste ${ }^{2}$, Juha Korpelainen ${ }^{1,3}$, Helvi Kyngäs ${ }^{4,5}$ \\ ${ }^{1}$ Oulu University Hospital, Finland \\ ${ }^{2}$ National Institute for Health and Welfare, Finland \\ ${ }^{3}$ Medical Research Center, Finland \\ ${ }^{4}$ University of Oulu, Finland \\ ${ }^{5}$ Research Unit of Nursing Science and Health Management, Finland
}

Received: January 27,2017

DOI: $10.5430 /$ jnep.v7n9p98
Accepted: April 5, 2017

URL: https://doi.org/10.5430/jnep.v7n9p98

\begin{abstract}
Background and objective: Frequent attender is the largest group to whom health care resources are allocated. Therefore potential interventions should be targeted at this group. Nurse-based case management considers frequent attenders' (FAs') needs for care as a whole and thus may reduce the use of other health services operators' resources. The objective of this study is to evaluate the effects of nurse-led case management on adherence to health regimens, depression, somatization and hypochondriasis in FAs.

Methods: The study is a quasi-experimental intervention trial, carried out as a prospective 2-year follow-up design with an intervention group $(n=285)$ and a control group $(n=435)$. The hypothesis was that nurse-led case management based intervention would have a positive impact on FAs' adherence to health regimens, somatization, hypochondriasis, and depression. The intervention patients received nurse-led case management which included an evaluation of patient needs and resources, an individualized care plan, the coordination of multidisciplinary services, and support for self-management. The control patients received the usual care, which means patient support and education during visits to the health center. The data were collected from at least 18 years of age frequent attenders by self-reported instruments: the Adherence of Chronic Disease Inventory, the Whiteley Index, the Symptom Checklist-90-R and Beck Depression Inventory, and one- and two-year follow-ups between October 2008 and May 2011.

Results: The intervention had an uplifting effect on the FAs' mood, and there was a statistically significant difference between the intervention patients and the control patients $(p=.03)$. Intervention reduced somatization with FAs, and it improved FAs' adherence to health regimens, but there was not a statistically significant difference between groups. Hypochondriasis increased in the intervention group compared to the control group after intervention $(p=.01)$.

Conclusions: Nurse-led case management has a positive effect on FAs' depression symptoms, somatization, and adherence to health regimens. The results will be useful in developing effective nurse-led interventions and support methods for FAs with complex long-term health conditions. Hypochondriasis increased in the intervention group although the purpose was for the community matron to discuss with FAs and reduce their concerns.
\end{abstract}

Key Words: Adherence, Frequent attender, Nurse-led case management, Chronic disease, Intervention

*Correspondence: Sari Hirsikangas; Email: sari.hirsikangas@ppshp.fi; Address: Oulu University Hospital, Oulu, Finland. 


\section{INTRODUCTION}

Frequent attendance in health care services is defined in many ways. It has been defined by counting contacts between patient and doctor. The contacts varies from 2 to 48 months during the time period; 12 months is commonly used. ${ }^{[1,2]}$ Different cut-off points for example the top 3\% or the top $10 \%$ or more of frequent attenders (FAs) having the most frequent contact are recommended. ${ }^{[3,4]}$ Hauswaldt, Himmel, \& Hummers-Pradier (2013) developed the contact-based definition of "frequent attendance" - which means the time period between two consecutive contacts measured in days. It contains no assumptions and it is easy to apply for diagnoses and demand analyses. ${ }^{[5]}$

In the present study, an FA is defined as a person who had $\geq$ 8 visits per year to a general practitioner in the local health center or $\geq 4$ visits per year to the university hospital. According to previous studies in Finland, the cut-off point of general practitioner was defined as 8 visits. ${ }^{[6-8]}$ In Finland, the number of older people is increasing, and consequently the number of FAs of health services will increase. The population part of people $\geq 65$ years of age is expected to increase from the current $19.9 \%$ to $26 \%$ by the year 2030 and remain broadly unchanged for the following ten years. ${ }^{[9]}$

FAs have a lot of physical disease, psychological distress, poor health beliefs, mental disorders and social difficulties. They need more information and support, and they have a lower quality of life compared with non-frequent attenders. ${ }^{[1,7,10]}$ The main reason for health care use is illness, and therefore the roles of psychological, social, and demographical factors are secondary. FAs is the group that might be expected to benefit from community matrons, ${ }^{[11]}$ who are experienced nurses with advanced practice skills using case management techniques with patients who have chronic diseases and who use of health care services intensively. Case management ensures a continuity of care for patients with complex care needs. ${ }^{[12]}$ Case manager assesses plans and implements, coordinates and evaluates the options and services required to meet an individual's extensive health needs. ${ }^{[13]}$

Community matron's role is to improve patient self-care and needs-based education. Patients need accurate control and support, and good coordination of responses in primary care. It is important to move away from reactive care to proactive and anticipatory care. ${ }^{[14]}$ It has been shown that the community matron is detected to be beneficial to patients provide the necessary services and psychosocial well-being. ${ }^{[15,16]}$ Qualitative studies have proposed that matrons enhanced patients' quality of life. ${ }^{[15,17]}$ There is evidence that nurse case management is effective in improving health outcomes for patients with chronic diseases: positive impact on patient

Published by Sciedu Press adherence to treatment and self-care, service use, satisfaction and quality of life and functionality. ${ }^{[18]}$

Sargent, Pickard \& Sheaff (2007) proposed that psychosocial support from a community matron improved mood, reduced stress, improved the ability to cope in patients with highly complex long-term conditions and helped to promote a feeling of being cared for. ${ }^{[15]}$ It is known that a nurse's 'relief of psychological symptoms' improved a feeling among patients that they were cared for. ${ }^{[19]}$ Smith et al. (2006) showed that long-term intervention by primary care professionals improved medically unexplained symptoms in FAs' mental health. ${ }^{[20]}$

Brown, Reeves, Meyerson \& Korzeniewski (2006) suggested that matrons improved older people's complicated long-term health conditions, reduced the workload of general practitioners, and reduced the need for psychological and social care. ${ }^{[16]}$ Community matrons may have a beneficial effect on patients' access to services and advocacy, psychosocial support, and perceptions of their care. ${ }^{[14]}$

Althaus et al. (2011) found that interventions targeting FAs may reduce the use of emergency departments (ED). Case management, the most frequently described intervention, reduced ED costs and improved clinical and social outcomes. ${ }^{[21]}$ In contrast, the Lee and Davenport (2006) study on the effect of nurse case management interventions on reducing the volume of visits of FAs of emergency departments was not proven. ${ }^{[22]}$ Evidence from Reinius et al. (2013) showed that nurse-led telephone-based case-management intervention reduced health care utilization for FAs in emergency department. ${ }^{[23]}$ According to Alyson et al. (2012), case management could not reduce the risk of unplanned hospital admissions in older people when compared with usual care. ${ }^{[24]}$

Some previous adherence studies have shown that interventions for improving adherence to care did not indicate statistically significant differences between the test and control groups of people with chronic disease. ${ }^{[16,25]}$ There is some intervention studies which have indicate positive effects on adherence in patients with hypertension and glaucoma. ${ }^{[26,27]}$ There are contradictory results as to whether or not community matron based interventions are effective.

There have been widely studied adherence to health regimens and their associated factors in patients with chronic disease. ${ }^{[8,27,28]}$ There have been fewer studies that examine the impact of case management intervention on somatization, hypochondriasis, and depression with FAs. The effects of interventions for enhancing medication have been inconsequent. ${ }^{[29]}$ However, electronic searches from 1967 
to 2004 showed that various interventions are effective in improving medication adherence, but only a few affected clinical outcomes significantly in chronic medical conditions. ${ }^{\text {[28] }}$ Kurikkala, Kääriäinen, Kyngäs \& Elo (2015) found that individual and group counseling interventions and technologyoriented counseling interventions with the elderly are effective and they can improve adherence and also enhance treatment results. ${ }^{[30]}$

FAs need services that are person-centered and take account of existing health conditions. Primary care services should meet the various needs of FAs with chronic disease and to decrease societal consequences. ${ }^{[31]}$

Based on the earlier literature, the hypothesis is that nurse-led case management based intervention would have a positive impact on FAs' adherence to health regimens, somatization, hypochondriasis, and depression.

\section{Aim of the study}

The aim of this study is to evaluate the effects of nurse-led case management on adherence to health regimens, bodily and depression symptoms, and hypochondriasis in frequent attenders. This is important issue to study because to improve FAs' coping in daily life, we need to know what kinds of support and counseling are effective.

\section{METHOD}

\subsection{Design}

The study design is a quasi-experimental intervention trial, carried out as a prospective 2-year follow-up design. This quasi-experimental study occurred in the real-life settings, where patients could not be randomized to experimental and control groups, and thus the study lacks full experimental control.

\subsection{Settings and sample}

The study was conducted at seven municipal health centers in northern Finland, in rural areas where health services are not widely available and distances are long. At times there is a lack of professionals (doctors, social workers, and psychologists). The study emphasizes the importance of the community matron type of approach, which can produce good results with FAs in this region.

The sample of health care FAs was collected retrospectively for the period 2006-2008 from electronic medical records at municipal health centers and Oulu University Hospital. This study is practical in nature, so all FAs over three years, wanted to reach out and offer them the opportunity for intervention and the sample size was sufficient for group comparison according to e.g. background factors. According to previous Finnish studies, patients who made at least eight outpatient visits per year to a general practitioner (GP) in the local health center were defined as FAs of medical services. ${ }^{[6-8,10]}$ Patients were also defined as FAs if they had made at least four outpatient visits per year to the university hospital. ${ }^{[32]}$ Because the aim was to examine the use of health services as a whole in order to develop health care services, specialized care was selected for inclusion.

One criterion for inclusion was a minimum age of 18 and outpatient visits with face-to-face contacts. Exclusion criteria included terminal hospice care, visits for serial treatment of the same illness, dementia, mental retardation, psychotic illness, cancer palliative care, pregnancy or delivery, inability to give informed consent, and they did not participate in other study intervention in the same time.

There were 720 patients in seven health centers that met the inclusion criteria: 613 FAs of primary care and 107 FAs of specialized care. Community matrons and researchers went through one by one person and verified that they were suitable for research. They sent an invitation letter and a semistructured postal questionnaire to participate in the study three times between October 2008 and May 2009, spring 2010, and spring 2011. Participants were asked for their written informed consent to the study. The final group for the case management intervention consisted of 285 FAs, and the control group consisted of 435 FAs. Because the number of FAs of special care is smaller than the number of FAs of primary care, the data does not allow for an analysis of the difference between those getting primary care and those getting specialized care. The flowchart of the participants is described in Figure 1.

\subsection{Data collection}

Adherence to health regimens among people with chronic disease was measured the self-reported Adherence of People with Chronic Disease Instrument (ACDI) developed by Kyngäs (1999). ${ }^{[33]}$ The instrument consisted of 38 items, with a five-point Likert scale ranging from agreement to indecision and disagreement. The following factors were used in this study: adherence to health regimens (taking medication, feeling responsible, carrying out self-care) and support (support from nurses, physicians, and relatives). Other self-reported instruments used were depression symptoms as measured by Raitasalo's modification of the short form of the Beck Depression Inventory. ${ }^{[34]}$ It is a 14 -item instrument with a five-point Likert scale. The scores for severity of depression are calculated from questions 1-13, with depression sum score ranges from 0-39. Hypochondriacal worries and beliefs were measured by the Whiteley Index. ${ }^{[35]}$ It consists of 14 items with a five-point Likert scale ranging from strong 
agreement to strong disagreement. The Symptom Checklist90-R was used to measure somatization. ${ }^{[36]}$ It contains 12 claims with a dichotomous scale on a range of symptoms, and it reflects distress arising from bodily perceptions. All instruments are valid, reliable, and were tested in earlier studies.

\subsection{Intervention}

The intervention was implemented in each of the four health centers by an experienced public health nurse (community matron). Before intervention, the nurses received five days of practical training and theory that included the following topics: case management, self-management support, treatment, and medical components of chronic diseases. The training was carried out by Oulu University Hospital and the University of Oulu. Community matrons and doctors discussed the cooperation and division of labor between primary care and specialized care. To train the community matrons, real patient cases provided by the doctors from the university hospital and health center were used. In addition, the community matrons received regional education organized by Oulu University Hospital.

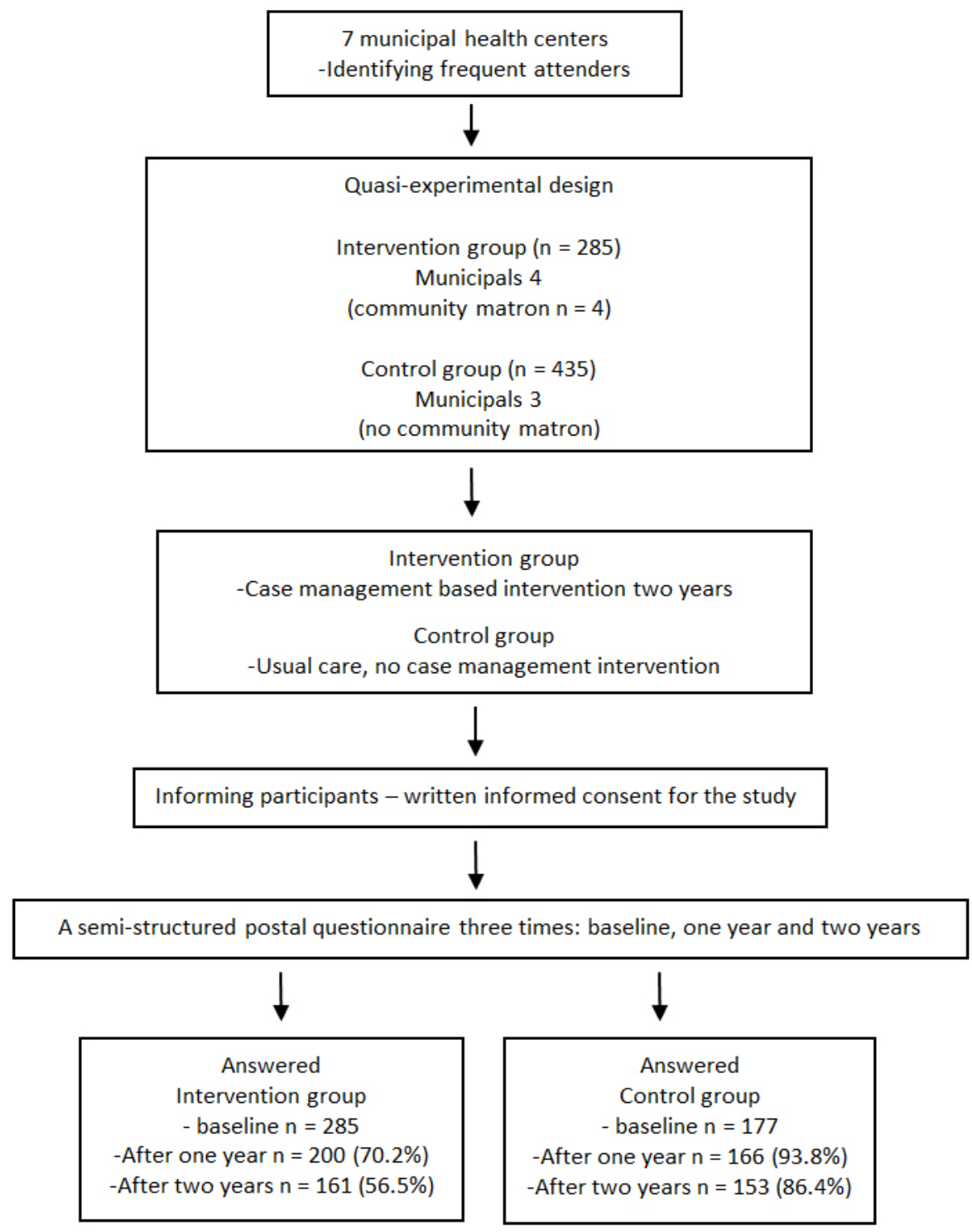

Figure 1. Flowchart of the participants

The intervention groups consist of 285 FAs. Each community matron was responsible for 50-90 FAs care and service coordination. The intervention contained the following main elements: an evaluation of FAs needs and resources, an individualized care plan, and the coordination of multidisciplinary services and support for self-management. The 
model highlighted regular contact, ensuring a continuity of care, constructing a confidential care relationship, support for the patient's capabilities and patient-oriented education, and active self-management support. Before the consultation, the community matron reviewed the FA's history and medical records. The matrons invited the FAs to visit the health center to determine the suitability and willingness to participate in the study. The FAs visited their own community matron throughout the two-year period and could be connected to all health-related issues. An individual and customer-oriented care plan was a key factor for the FAs, which was made with different professional groups by a community matron.

The FAs of control group $(n=435)$ received the usual care, which means that they visited the health care center as needed. The designated community matron was not available to them.

\subsection{Data analysis}

Statistical analyses were executed by using Statistical Package for the Social Sciences for Windows 22. Percentages, frequencies, $p$-values and the chi-square test were used to describe the data. Differences between the groups and measurements were analyzed by the paired samples $T$-test and Mann-Whitney test $p$-value.

\subsection{Ethical considerations}

The Finnish Advisory Board on Research Integrity (2012) has defined the ethical research guidelines which were taken into account when making this study. This type of study does not need approval from an official research ethics committee according to Finnish law $(2010 / 794,2015 / 143)$. The participating communities gave administrative approval to the study. The participants were informed in a cover letter that their participation was voluntary and could be interrupted at any given time. All participants signed a voluntary consent form.

\section{RESUltS}

There was no statistically significant difference between intervention and control group participants by age or gender. It seems that the majority of the intervention group participants had elementary education, which provides the knowledge and skills needed in life, while the majority of the control group participants had vocational education, which lead to a qualification or be in the form of further education. One or more chronic diseases were diagnosed in $268(n=285)$ of the intervention participants and $154(\mathrm{n}=173)$ of the control participants. Information of diseases was self-reported, physician-diagnosed diseases and disease had lasted more than three months. The background information of the participants is presented in Table 1 .

According to the results, the members of the intervention group had improved adherence to health regimens after two years of intervention compared to the control group, but there was no statistically significant difference $(p=.067)$. A similar positive effect is noticeable in FAs' responsibility for self-care in the intervention group after one and two years, but without statistical significance $(p=.096)$.

Table 1. The background information of the participants $(n=720)$

\begin{tabular}{|c|c|c|c|c|c|c|c|c|c|c|c|c|c|c|c|c|c|c|}
\hline \multirow{3}{*}{ Charasteristics } & \multicolumn{6}{|c|}{ Baseline } & \multicolumn{6}{|c|}{1 year } & \multicolumn{6}{|c|}{2 years } \\
\hline & \multicolumn{2}{|c|}{ Intervention } & \multicolumn{2}{|c|}{ Control } & \multirow{2}{*}{$\chi^{2}$} & \multirow{2}{*}{$p$} & \multicolumn{2}{|c|}{ Intervention } & \multicolumn{2}{|c|}{ Control } & \multirow{2}{*}{$\chi^{2}$} & \multirow{2}{*}{$p$} & \multicolumn{2}{|c|}{ Intervention } & \multicolumn{2}{|c|}{ Control } & \multirow{2}{*}{$\chi^{2}$} & \multirow{2}{*}{$p$} \\
\hline & $\mathbf{n}$ & $\%$ & $\mathbf{n}$ & $\%$ & & & $\mathbf{n}$ & $\%$ & $\mathbf{n}$ & $\%$ & & & $\mathbf{n}$ & $\%$ & $\mathbf{n}$ & $\%$ & & \\
\hline Female & 184 & 65 & 117 & 66 & \multirow{3}{*}{0.114} & \multirow{3}{*}{.736} & 137 & 69 & 102 & 61 & \multirow{3}{*}{1.992} & \multirow{3}{*}{.158} & 108 & 67 & 95 & 62 & \multirow{3}{*}{0.854} & \multirow{3}{*}{.355} \\
\hline Male & 101 & 35 & 60 & 34 & & & 63 & 31 & 64 & 39 & & & 53 & 33 & 58 & 38 & & \\
\hline Total & 285 & & 177 & & & & 200 & & 166 & & & & 161 & & 153 & & & \\
\hline \multicolumn{17}{|l|}{ Age } & \multirow{5}{*}{1.261} & \multirow{5}{*}{.532} \\
\hline $18-39$ & 37 & 13 & 21 & 12 & \multirow{4}{*}{0.151} & \multirow{4}{*}{.927} & 20 & 10 & 13 & 8 & \multirow{4}{*}{1.065} & \multirow{4}{*}{.587} & 9 & 6 & 8 & 5 & & \\
\hline $40-64$ & 134 & 47 & 83 & 47 & & & 92 & 46 & 72 & 43 & & & 71 & 44 & 58 & 38 & & \\
\hline$\geq 65$ & 114 & 40 & 73 & 41 & & & 88 & 44 & 81 & 49 & & & 81 & 50 & 86 & 57 & & \\
\hline Total & 285 & & 177 & & & & 200 & & 166 & & & & 161 & & 152 & & & \\
\hline \multicolumn{5}{|l|}{ Education level } & \multirow{4}{*}{3.311} & & & & & & & & & & & & & \\
\hline $\begin{array}{l}\text { Elementary } \\
\text { education }\end{array}$ & 153 & 55 & 79 & 46 & & 060 & 106 & 54 & 51 & 42 & 2004 & 046 & 85 & 54 & 48 & 45 & 2102 & 120 \\
\hline $\begin{array}{l}\text { Vocational } \\
\text { education }\end{array}$ & 125 & 45 & 92 & 54 & & .009 & 90 & 46 & 69 & 58 & 5.994 & .040 & 72 & 46 & 59 & 55 & 2.192 & .139 \\
\hline Total & 278 & & 171 & & & & 196 & & 120 & & & & 157 & & 107 & & & \\
\hline
\end{tabular}

The intervention had no statistically significant effect on FAs' responsibility for self-care or adherence to the medication year and the two-year follow-up in the intervention and con- trol groups. The FAs did not feel that the intervention would have improved support from nurses, physicians, or relatives. 
Table 2. FAs' adherence to health regimens, responsibility for self-care, adherence to medication, support from nurses, physicians and relatives in baseline, one year and two years after intervention in the control and intervention groups

\begin{tabular}{|c|c|c|c|c|c|c|}
\hline \multirow{2}{*}{ Variables } & \multicolumn{2}{|l|}{ Baseline } & \multicolumn{2}{|l|}{1 year } & \multicolumn{2}{|l|}{2 years } \\
\hline & Median & $p$-value* & Median & $p$-value* & Median & $p$-value* \\
\hline \multicolumn{7}{|c|}{ Adherence to health regimens } \\
\hline Intervention & 53 & \multirow{2}{*}{.112} & 52 & \multirow{2}{*}{.880} & 53 & \multirow{2}{*}{.067} \\
\hline Control & 52 & & 51 & & 52 & \\
\hline \multicolumn{7}{|c|}{ Responsibility for self-care } \\
\hline Intervention & 24 & \multirow{2}{*}{.411} & 24,5 & \multirow{2}{*}{.173} & 25 & \multirow{2}{*}{.096} \\
\hline Control & 23 & & 23 & & 24 & \\
\hline \multicolumn{7}{|c|}{ Adherence to medication } \\
\hline Intervention & 15 & \multirow{2}{*}{.007} & 15 & \multirow{2}{*}{.912} & 15 & \multirow{2}{*}{.102} \\
\hline Control & 15 & & 15 & & 15 & \\
\hline \multicolumn{7}{|c|}{ Support from nurses } \\
\hline Intervention & 16 & \multirow{2}{*}{.205} & 16 & \multirow{2}{*}{.330} & 16 & \multirow{2}{*}{.227} \\
\hline Control & 17 & & 17 & & 17 & \\
\hline \multicolumn{7}{|c|}{ Support from physicians } \\
\hline Intervention & 16 & \multirow{2}{*}{.411} & 15 & \multirow{2}{*}{.430} & 15 & \multirow{2}{*}{.237} \\
\hline Control & 16 & & 16 & & 16 & \\
\hline \multicolumn{7}{|c|}{ Support from relatives } \\
\hline Intervention & 19 & \multirow{2}{*}{.003} & 18 & \multirow{2}{*}{.894} & 18 & \multirow{2}{*}{.251} \\
\hline Control & 18 & & 17 & & 17 & \\
\hline
\end{tabular}

* Mann-Whitney Test $p$-value

Comparing the means by paired samples $T$-test showed that somatization was -0.25 unit less in the intervention group and -0.1 unit less in the control group after intervention. The reduction in somatization was -0.15 unit greater in the intervention group than in the control group. The difference was not statistically significant $(p=.580)$. The differential of $-0.15(95 \%$ CI $-0.7,0.4)$ indicates that the intervention group somatization reduction may have been greater than in the control group and the intervention had a positive impact on the reduction in somatization.

From the paired samples $T$-test, it was seen that hypochondriasis increased in the intervention group compared to the control group after intervention. There was a statistically significant difference, with an independent $T$-test $p$-value of .01 (CI 95\% 0.45, 1.84).

FAs in the intervention group had a lower median (2) in depression symptoms after intervention than the control group (3), with a median test $p$-value of .03. This suggests that intervention had an uplifting effect on mood.

\section{Discussion}

This study presents highlights the effect of nurse-led case management based intervention on FAs' adherence to health

Published by Sciedu Press regimens and on depression symptoms, hypochondriasis, and somatization in primary care in Finland. The main results of this study were that the intervention had an uplifting effect on FAs' mood and a positive impact on the reduction in somatization. According to the patients' experiences, it is important that the community matron can be easily contacted when they feel anxious, because it reassures them and gives them a sense of security. ${ }^{[14]}$ It can be assumed that these have a positive effect on FAs' mood and somatization. Nurses have a significant role in the care of patients with chronic diseases. These findings are in line with earlier studies. Sargent et al. (2007) suggested that support from a community matron helped to improve the mood in patients with complex long-term conditions. ${ }^{[15]}$ Another study showed that long-term, multiprofessional intervention by primary care providers would lead to a clinically significant improvement in mental function. ${ }^{[20]}$ Allen and Fabri (2005) reported that a community aged care nurse practitioner service could provide quality comprehensive nursing care and positively affect customers psychological and physical symptoms. ${ }^{[19]}$

The study's findings suggest that the intervention improved adherence to health regimens in the intervention group compared to the control group, although there were no statistically significant differences. This is in line with an earlier 
review where significantly positive results were reported on the impact of nurse case management on patients' adherence to treatment. ${ }^{[18]}$ Lunnela et al. (2011) also showed that Webbased intervention had led to better adherence, although there was no statistically significant difference. ${ }^{[27]}$ It is known that, the consequences of poor adherence to long-term therapies are relevant; increased health care costs and poor health outcomes. The health of the population could benefit more from effective adherence interventions than improving any specific medical treatments. ${ }^{[37]}$ It can be expected that a case management approach may benefit for FAs to meet their care needs and to increase adherence to health regimens. According to our understanding, it seems that FAs need regular, anticipatory nurse-led care based on individual needs with a holistic approach. It enables effective counseling and provides support to improve adherence to health regimens.

The nurse-led case management based intervention had a positive effect on FAs' responsibility for self-care in the intervention group, but there was no statistically significant difference. This is supported by a previous study where lifestyle changes were found as a result of the intervention in persons with risk of cardiovascular disease and a nurse-led heart failure clinic intervention, which improved survival and the self-care behavior in patients with heart failure. ${ }^{[38]}$ According to earlier studies, support and education from healthcare personnel are crucial for self-care and coping with illness. ${ }^{[25,39,40]}$ It's believable that in this study, FAs with complex care needs know that their own activity will have a significant impact on their future well-being and they take responsibility for their own health. The role of patients is to be well-informed active partners or collaborators in their own care. Health professionals' role is to help patients make decisions to achieve their goals. Appropriate care recommendations, expert advices, and support are the solutions to help the patient to overcome their barriers. The ideal is that professionals become responsible to their patients instead of feeling responsible for them. ${ }^{[41]}$

Intervention did not improve FAs' adherence to medication. This differs from previous research which showed that various types of interventions can improve medication adherence in chronic conditions. ${ }^{[28]}$ Pharmacist intervention can also effectively increase medication adherence. ${ }^{[42]}$ Based on the authors'earlier study, foundings were that FAs' adherence to a medication regimen was $90 \%$ in this intervention and the control group. ${ }^{[8]}$ They are already highly adherent to medication. Based on our understanding, the community matron's role is to keep FAs adhered to medication regimens because it improves their quality of life keeping their chronic diseases under control.
The results showed no statistically significant differences between the intervention group and the control group in getting support from the health staff or relatives, according to each follow-up measurement. Authors' earlier study showed that support from relatives or healthcare providers was not a significant predictor for good adherence in this study group and the result was the opposite of the findings from previous studies. ${ }^{[8,43-45]}$ Based on the authors' view, the patients in this study were FAs of health care services and they had a large number of contact with health care providers; therefore they did not benefit from further special support during the intervention. Sometimes case management can't help FAs any more.

Hypochondriasis increased in the intervention group, and there was a statistically significant difference between the control group and the intervention group. This may be due to the fact that a given intervention with special attention turned FAs' thoughts toward more self-monitoring. The purpose is for the community matron to discuss with FAs about their issues in order to reduce their concerns.

The study was conducted in rural areas, where distances are long, health services are not widely available, and sometimes there is a lack of professionals. Based on this study, the community matron approach may have a positive impact on issues like the rural area and can be used to achieve good results with FAs.

\subsection{Limitations}

One limitation of this study is that instruments are selfreported; when they are used, social desirability by the respondent is always present. However, this study has many strengths. The perspective of the research theme is current and it is new compared to previous studies. The other strength is that in both the intervention and the control groups, the response rates were rather high compared to the baseline: For the intervention group, it was $70.2 \%$ (one year) and $56.5 \%$ (two years). For the control group, it was $93.8 \%$ (one year) and $86.4 \%$ (two years). The third strength is carefully selected sample of FAs. That information was based on medical records. In addition, the validity and reliability of the instruments used were found to be high and instruments are commonly used.

\subsection{Relevance to clinical practice}

To improve FAs' adherence with health regimens, somatization, hypochondriasis and depression, open two-way communication with a community matron is needed. He or she helps patients discuss their adherence and the factors that influence it and helps plan their care together during various professional groups. Without the knowledge of a patient's 
individual needs, an individual and customer-oriented care plan is impossible. FAs with complex care needs need frequent support and encouragement to manage their chronic illnesses and treatment.

Results of research will be useful as well as will pave the way for developing effective interventions and support methods for FAs with complex long-term health conditions. As the study shows, community matron model has positive effects in FAs' welfare in many sections, and it would be recommendable to use more widely.

\section{Conclusions}

The main result of this study is that the FAs' mood improved with this nurse-led case management and statistically significant differences were found. The nurse-led case management intervention had a positive impact on the reduction of somatization and the improvement of FAs' adherence to health regimens, although no statistically significant differences were found. However, it is remarkable that hypochondriasis increased in the intervention group during the intervention. This indicates that a community matron's active contact with FAs does not lead to a decrease in hypochondriasis. Without taking into account the results of hypochondriasis, hypothesis that were set were proven as true. To better understand the implications of interventions, further research is needed. We should find out what issues make intervention effective.

\section{ACKNOWLEDGEMENTS}

The authors thank the staff of health centers in northern Finland (in Ii, Pudasjärvi, Utajärvi, Vaala, Kiiminki, Muhos, and Taivalkoski) for data collection.

\section{CONFLICTS OF INTEREST Disclosure}

The authors have no conflict of interest.

\section{REFERENCES}

[1] Vedsted P, Christensen MB. Frequent attenders in general practice care: a literature review with special reference to methodological considerations. Publ Health. 2005; 119: 118-137. http: //dx.doi.org/10.1016/j.puhe.2004.03.007

[2] Smits FT, Brouwer HJ, ter Riet G, et al. Epidemiology of frequent attenders: a 3-year historic cohort study comparing attendance, morbidity and prescriptions of one-year and persistent frequent attenders. BMC Public Health. 2009; 9: 36. http://dx. doi .org/10.1186 /1471-2458-9-36

[3] Smits F, Mohrs J, Beem E, et al. Defining frequent attendance in general practice. BMC Fam Pract. 2008; 9: 21. http://dx. doi.o $\mathrm{rg} / 10.1186 / 1471-2296-9-21$

[4] Luciano JV, Fernandez A, Pinto-Meza A, et al. Frequent attendance in primary care: comparison and implications of different definitions. Br J Gen Pract. 2010 Feb; 60(571): 49-55. http: //dx.doi.org/10.3399/bjgp10X483139

[5] Hauswaldt J, Himmel W, Hummers-Pradier E. The inter-contact interval: a new measure to define frequent attenders in primary care. BMC Family Practice. 2013; 14: 162. htpp://dx.doi.org/10. 1186/1471-2296-14-162

[6] Jyväsjärvi S, Keinanen-Kiukaanniemi S, Vaisanen E, et al. Frequent attenders in a Finnish health centre: morbidity and reasons for encounter. Scand J Prim Health Care. 1998; 16: 141-148. http://dx.doi.org/10.1080/028134398750003089

[7] Koskela T. The Prognostic Risk Factors for Long-Term Frequent Use of the Primary Health Care Services. Doctoral dissertation. Kuopio University Publications D. Medical Sciences 425. University of Kuopio. Kuopio: 2008.

[8] Hirsikangas S, Kanste O, Korpelainen J, et al. Adherence to health regimens among frequent attenders of Finnish healthcare. Int J Circumpolar Health. 2016; 75: 30726. http://dx.doi.org/10.34 02/ijch.v75.30726

[9] Tilastokeskus, Statistics Finland. Suomen virallinen tilasto. Available from: http://www.stat.fi/til/vaenn/2015/vaenn_2 015_2015-10-30_tie_001_fi.html

Published by Sciedu Press
[10] Jyväsjärvi S, Joukamaa M, Vaisänen E, et al. Somatising frequent attenders in primary health care. J Psychosomat Res. $2001 \mathrm{Apr}$; 50: 185192. http://dx.doi.org/10.1016/S0022-3999(00)00217-8

[11] Rennemark M, Holst G, Fagerstrom C, et al. Factors related to frequent usage of the primary healthcare services in old age: findings from The Swedish National Study on Aging and Care. Health Soc Care Comm. 2009 Jan; 17: 304-311. http://dx.doi .org/10.11 $11 / j .1365-2524.2008 .00829 . x$

[12] Challis D, Hughes J, Berzins K, et al. Self-care and case management in long-term conditions: the effective management of critical interfaces. Report for the National Institute for Health Research Service Delivery and Organisation programme. 2010. Available from: http://www.pssru.ac.uk/pdf/MCpdfs/SCCMfr.pdf

[13] Case Management Society of America. Standards of Practice for Case Management. Revised 2010. Available from: http://www.cmsa.org/portals/0/pdf/memberonly/stan dardsofpractice.pdf

[14] Williams V, Smith A, Chapman L, et al. Community matrons - an exploratory study of patients' views and experiences. J Adv Nurs. 2010 Jan; 67(1): 86-93. http://dx.doi.org/10.1111/j.1365-264 8.2010.05458. $\mathrm{x}$

[15] Sargent P, Pickard S, Sheaff R. Patient and carer perceptions of care management for long-term conditions. Health \& Social Care in the Community. 2007 Nov; 15(6): 511-519. http://dx.doi.org/10. $1111 / j .13652524 .2007 .00708 \cdot x$

[16] Brown MD, Reeves MJ, Meyerson K, et al. Randomized trial of a comprehensive asthma education program after an emergency department visit. Annals of Allergy, Asthma \& Immunology. 2006 July; 97(1): 44-51. http://dx.doi.org/j.1016/S1081-1206(10)6 1368-3

[17] Leighton Y, Clegg A, Bee A. Evaluation of community matron services in a large metropolitan city in England. Quality in Primary Care. 2008; 16(2): 83-9. PMid:18700084

[18] Sutherland D, Hayter M. Structured review: Evaluating the effectiveness of nurse case managers in improving health outcomes in three 
major chronic diseases. J Clin Nurs. 2009 Nov; 18(21): 2978-2992. http://dx.doi.org/10.1111/j.1365-2702.2009.02900.x

[19] Allen J, Fabri AM. An evaluation of a community aged care nurse practitioner service. Journal of Clinical Nursing. 2005 Nov; 14(10): 1202-9. http://dx.doi.org/10.1111/j.1365-2702 . 2005.01199. $x$

[20] Smith R, Lyles J, Gardiner J, et al. Primary Care Clinicians Treat Patients with Medically Unexplained Symptoms: A Randomized Controlled Trial. Journal of General Internal Medicine. 2006 July; 21(7): 671-677. http://dx.doi.org/10.1111/j.1525-1497. 2006.00460.x

[21] Althaus F, Paroz S, Hugli O, et al. Effectiveness of Interventions Targeting Frequent Users of Emergency Departments: A Systematic Review. Annals of Emergency Medicine. 2011 July; 58(1): 41-52. http: //dx.doi.org/10.1016/j.annemergmed.2011.03.007

[22] Lee KH, Davenport L. Can Case Management Interventions Reduce the Number of Emergency Department Visits by Frequent Users? Health Care Manager. 2006 April/June; 25(2): 155-9. https://doi.org/10.1097/00126450-200604000-00008

[23] Reinius P, Johansson M, Fjellner A, et al. A telephone-based casemanagement intervention reduces healthcare utilization for frequent emergency department visitors. European Journal of Emergency Medicine. 2013 Jun; 20(5): 327-334. http://dx.doi . org/10 . 10 97/MEJ.0b013e328358bf5a

[24] Huntley AL, Thomas R, Mann M, et al. Is case management effective in reducing the risk of unplanned hospital admissions for older people? A systematic review and meta-analysis. Family Practice. 2013 Jun; 30: 266-275

[25] Kääriäinen M, Kyngäs H. Patient counselling in nursing research published during 1995-2002 [Finnish]. Hoitotiede. 2005; 17; 208216.

[26] Green BB, Cook AJ, Ralston JD, et al. Effectiveness of home blood pressure monitoring, Web communication, and pharmacist care on hypertension control: a randomized controlled trial. Journal of the American Medical Association. 2008; 299(24): 2857-2867. http://dx.doi.org/10.1001/jama.299.24.2857

[27] Lunnela J, Kääriäinen M, Kyngäs H. Adherence of Finnish people with glaucoma to treatment plans and connected factors. Int J Circumpolar Health. 2011; 70(1): 79-89. PMid:21062571 https: //doi.org/10.3402/ijch.v70i1.17796

[28] Kripalani S, Xiaomei Y, Haynes B. Interventions to Enhance Medication Adherence in Chronic Medical Conditions. Arch Intern Med 2007; 167(6): 540-9. PMid:17389285 https ://doi.org/10.100 1/archinte.167.6.540

[29] Nieuwlaat R, Wilczynski N, Navarro T, et al. Interventions for enhancing medication adherence. Cochrane Database Syst Rev. 2014 Nov 20; (11): CD000011. http://dx.doi.org/10.1002/14651 858. CD000011. pub4

[30] Kurikkala P, Kääriäinen M, Kyngäs H, et al. Interventions designed to promote adherence and their effects in elderly - integrative review. Hoitotiede. 2015; 27: 3-17 [in Finnish].
[31] MSSS. Stratégie de prévention et de gestion des maladies chroniques et Plan d'action 2008-2013. Québec: Ministère de la santé et des services sociaux.

[32] Hansagi O, Olsson M, Sjöberg S, et al. Frequent use of the hospital emergency department is indicative of high use of other health care services. Ann Emerg Med. 2001; 37(6): 561-7. http://dx. doi .o $\mathrm{rg} / 10.1067 / \mathrm{mem} .2001 .111762$

[33] Kyngäs $\mathrm{H}$. The development of an instrument to measure the compliance of adolescents with diabetes. Hoitotiede. 1999; 11: 151-162 [in Finnish].

[34] Beck AT, Ward $\mathrm{CH}$, Mendelson $\mathrm{M}$, et al. An inventory for measuring depression. Arch. Gen. Psychiatry. 1961; 4: 56171. PMid:13688369 https://doi.org/10.1001/archpsyc. 196 1.01710120031004

[35] Pilowsky I. Dimensions of hypochondriasis. Br J Psychiatry. 1967 Jan; 113(494): 89-93. http://dx.doi.org/10.1192/bjp.113 .494 .89

[36] Derogatis LR, Lipman RS, Covi L. SCL-90: an outpatient psychiatric rating scale - preliminary report. Psychopharmacol Bull. Jan 1973; 9(1): 13-28. PMid:4682398

[37] World Health Organization. Adherence to long-term therapies: evidence for action. Switzerland. 2003.

[38] Ylimäki EL, Kanste O, Heikkinen H, et al. The effects of a counseling intervention on lifestyle change in people at risk of cardiovascular disease. Eur J Cardiovasc Nurs. 2015; 14(2): 153-161. http://dx.doi.org/10.1177/1474515114521725

[39] Kääriäinen M, Kyngäs H, Ukkola L, et al. The conceptions of patients concerning counselling. [Finnish]. Tutkiva hoitotyö. 2005; 3: 10-15.

[40] Kaimal AJ, Cheng YW, Bryant AS, et al. Google obstetrics: who is educating our patients? American Journal of Obstetrics and Gynecology. 2008 Jun; 198(6): 682.e1-5. http://dx. doi .org/10.10 $16 / j \cdot$ ajog. 2008.03.030

[41] Funnell M, Anderson R. Empowerment and Self-Management of Diabetes. Clinical Diabetes. 2004 Jul; 22(3): 123-127. https: //doi.org/10.2337/diaclin.22.3.123

[42] Morgado M, Rolo S, Castelo-Branco M. Pharmacist intervention program to enhance hypertension control: a randomised controlled trial. International Journal of Clinical Pharmacy. 2011 Feb; 33(1): 132-40. http://dx.doi.org/10.1007/s11096-010-9474-x

[43] Lahdenperä $T$, Wright $C$, Kyngäs H. Development of a scale to assess the compliance of hypertensive patients. Int J Nurs Stud. 2003 Sept; 7: 677-684. http://dx.doi.org/10.1016/S0020-7489(02)0 0110-4

[44] Lunnela J, Kyngäs H, Hupli M. Compliance of a patient with glaucoma and associated factors. Hoitotiede. 2006; 18: 151-9 [in Finnish]

[45] Kääriäinen M, Paukama M, Kyngäs H. Adherence with health regimens of patients with warfarin therapy. J Clin Nurs. 2013; 22(12): 89-96. http://dx.doi.org/10.1111/j.1365-2702.2012 $.04079 . x$ 